\title{
PUBLICACÕES RECEBIDAS
}

Recebemos, e agradecemos:

Améticas - Periódico de divulgação do Serviço Gráfico do I.B.G.E. - Vol. XI, n. 1 - Janeiro de 1959. Rio de Tatheiro.

Boletim Britânico - Dezembro de 1958 - N. ${ }^{\circ} 121$ - Londres.

Boletim do C. P. E. - Orgão mensal de divulgação da Fundação Comissão de Planejamento Econômico do Estado da $\mathrm{Ba}$ hia. N. ${ }^{\circ} 5$ - Ano II - Janeiro de 1959 - Salvador, Bahia, Brasil.

Boletin de la Dirección General Impositiva Ministerio de Hacienda. Vol. 10 N. 61 - Enero, 19559 - Ano VI Buenos Aires, Argentina.

Boletim da Biblioteca do Exército - Ministério da Guerra - Rio de Janeiro.

Boletin de Gerência Administrativa - División de Imprenta - Departamento de Hacienda de Porto Rico. $N^{9}$ 82, Enero 1959 - Año XII.

Boletim Mensal da Federação das Indístrias do Distrito Federal - Departamento de Produtividade. N. ${ }^{\circ}$ 50, Janeiro 1959. Rio de Ianeiro.

Bôlsa de Mercadorias da Bahia-Filiado ao Conselho Interamericano de Comércio e Produção. Fevereiro de 1959. Bahia, Brasil.

Boletim das Pioneiras Sociais - Centro de Pesquisas Luiza Gomes de Lemo;. N. ${ }^{\circ} 6$. Janeiro. Vol. I - 1959. Rio de Janeiro, Brasil.

Brasilia - Revista da Companhia Urbanizadora da Nova Capital do Brasil $N^{\circ} 25$. Janeiro 1959 - Ano 3. Rio de Janeiro.

Brasil Açucareiro - Instituto do Açúcar e do Alcool. Ano XXIII. Vol. LIII. - N. ${ }^{\circ} 2$,

Fevereiro de 1959. Rio de Janeiro, Brasil.

Brasil - Mensual de la Oficina del Gobier:1o del Brasil en Paraguay. N. ${ }^{\circ} 4-$ Abril 1959. Assunción, Paraguay.
Brasil de Hoje - Economia, Finanças e Turismo. N. $0^{\circ}$ 56. Novembro e Dezembro de 1958. Ano XIII. Rio de Janeiro, Brasil.

Ciencias Politicas y Sociales - Revista de la Escola Nacional de Ciencias Politicas y Sociales. Universidad Nacional Autônoma de Mexico. N. ${ }^{\circ} 14$. Octubre y Diciembre, 1958. Año IV.

Crónica de la Unnesco - Boletin mensual publicado por el Centro Regional de la Unesco en el Hemisfério Occidental. N. ${ }^{\circ}$ 12. Diciembre 1958. Vol. IV - La Havana, Cuba.

Comércio de Cabotagem do Brasil - Serviço Gráfico do I.B.G.E. Anos de 1956/57. Rio de Janeiro, Brasil.

Departamento das Prefeituras Municipais Primeiro Congresso de Contatores Municipais do Rio Grande do Sul - 1959 R. G. S., Brasil.

Documentacion Administrativa - Boletin mensual de la Secretaria General Tecnica de la Presidencia del Gobierno. Ns. 15 e 16 - Madrid - Marzo y Abril, 1959. Madrid, España.

Essepevê - Ns. 20 e 21 - Ano IV - Janeiro/Fevereiro de 1959.

Estudos Sociais e Politicos - N. ${ }^{\circ} 5-1959$ - Revista Brasileira de Estudos Politicos - Imprensa da Universidade de Minas Gerais, Brasil.

Gaceta Judicial - Publicacion mensual del organo de la Corte Suprema de ?usticia de la Republica del Equador - LXI Serie nona - N. 1 - Enero/Abril 1958. Quito, Ecuador.

Idort - Revista de organização e produtividade do Instituto de Organização Racional do Trabalho, Comité Nacional Brasileiro, filiado ao Comité Internacional de l'Organization Scientifique (CIOS) - Ano XXVII - Ns. $325 / 26$ - São Paulo, Brasil.

Informações Sâbre a Escola de Serviço Público do D.A.S.P. e M.E.C. - Cursos 
de formação e aperfeiçoamento para o corrente ano. Ano I - N. ${ }^{\circ} 1-1959-$ Rio de Janeiro, Brasil.

Informacion Turidica - del Ministerio de Jus. ticia - Comision de Legislaciona Extran. jera. Ns. $186 / 87$ - Noviembro-Diciembro 1958 - San Bernardo - Madrid España.

Hospital dos Servidores do Estado - I.P.A.S.E. - N. ${ }^{\circ} \mathrm{V}$ - Ano III - Rio de Janeiro.

Jornal Oficial do Municipio de Ilhéus - Ano XXI - 69. ${ }^{\circ}$ da República - N. 2.053 - 3." feira, $17 / 2 / 59$.

Jus Documentação - do Ministério da Justiça e Negócios Interiores - Ano XII Janeiro/Março de $1959-\mathrm{N}^{\circ} 1$ - Rio de Janeiro, Brasil.

Jus Gentium - Diritto internacionnale - Vol. VI - N. 4 - 1959 - Roma, Itália .

Livros de Portugal - Boletim mensal do Grêmio Nacional dos Editores e Livreiros de Lisboa - N. ${ }^{\circ} 4$ - Abril de 1959 ... Portugal.

O Labor - Órgão do pessoal da Fábrica Presidente Vargas - Quinzenário - Ano XIV - N. ${ }^{\circ} 296$, de 15/3/59 - Estado de São Paulo, Brasil.

Mensagem Econômica - Órgão oficial da Associação Comercial de Minas e da Federação das Associações Comerciais de Minas Gerais - Publicação mensal N. 75 - Ano VII -- Março de 1959 Minas Gerais, Brasil.

Mensário Estatistico - Publicação do Ministério da Fazenda e do Serviço de Estatistica Economica e Financeira do Conselho Nacional de Estatistica - I.B.G.E. - N. 92 - Fevereiro de 1959 - Rio de Janeiro, Brasil.

Missão Cultural no Ulruguay - Primeiro centenário de juan Zorrilla de San Martin - 1957 - Rio de Janerio, Brasil.

Noticiório Espanhol - Publicação do Escri. tório de Propaganda Comercial do Brasil em Madrid - N. 19 - Janeiro de 1959 - Madrid, Espanha.

Noticiário das Nações Unidas - Ano IX N. 4 - Abril de 1959 - Rio de Janeiro.

Noticias de Portugal - Boletim semanal do Secretariado Nacional de Informação -
Palácio da Foz - Ano XII - Ns. 614, 616 e 617 , respectivamente de $7 / 2 / 59$, $21 / 2 / 59$ e $28 / 2 / 59$ - Lisboa, Portugal

Public Administration Review - The Journal of the American Society for Public Administration - Vol. XIX - Number I - Winter, 1959, Regimen Tributário Asociacion de Industriales, 1958/1958 _. República de olômbia.

Relatório da Divisão do Impôsto de Renda -das atividades do ano de 1956 - Rio de Janeiro, Brasil.

Revista do Club Municipal - Orgão oficial da Associação - Ns. 221/22 - Ano 1959, Março/Abril — Rio de Janeiro, Brasil.

Revista de Ciências Sociais - Revista publicada trimestralmente por el Colegio de Ciencias Sociales de la Universidad de Puerto Rico - Vol. II - N. 3 Spetiembre, 1958.

Revista do Conselho Nacional de Economia Ano VIII - N. ${ }^{\circ} 1$ - Janeiro/Fevereiro de 1959 - Rio de Taneiro, Brasil.

Revista da Escola de Agronomia e Veterinária da Universidade do Rio Grande do $\mathrm{Sul}$ - Vol. II - fasciculo I - Dezembro de 1958 - Rio Grante do Sul, Brasil.

Revista de Derecho y Ciencias Politicas Organo de la Faculted de Derecho de la Universidad Nacional Mayor de San Marcos - Año XXII - Primer, segundo y tercer cuatrimestres - Ns. I - II III - 1958 - Lima, Peru.

Revista Fiscal e de Legislação de Fazenda .. Publicação quinzenal sistematiza.ła e com explicações e comentários das leis, decretos e decisões administrativas e judiciárias, sôbre matéria fazendária - Ano $\mathrm{XXX}$ - Ns. 2 e 3 , respectivamente de $28 / 2 / 59$ e de $31 / 3 / 59$ - Rio de Janeiro.

Revista de Finanças Públicas - Anı XIX N. ${ }^{\circ} 205$ - Janeiro/Fevereiro de 1959 Editada pelo Conselho Técnico de Eco. nomia e Finanças do Ministério da $\mathrm{Fa}$ zenda - Rio de Janeiro, Brasil.

Revista do I.R.B. - Publicação bimestral do Instituto de Resseguros do Brasil - Ano XIX - N. ${ }^{\circ} 113$ - Fevereiro de 1959 Rio de Janeiro.

Revista dos Municipios - Orgãos do Departamento das Prefeituras - Ano I - Maio 
de 1959 - Estado do Rio Grande do Sul Brasil.

Paraná Éconômico - Órgão defensor dos interêsses da produção do Estado - - Ano VI - N. 72 - Março de 1959 - Es. tado do Paraná, Brasil.

.. De Portugal Para o Brasil - Publicação do Escritório de Propaganda e Expansão Comercial do Brasil em Lisboa - Ano $\mathrm{XI}$ - N. ${ }^{\circ} 1$ - Janeiro de 1959 - Lisboa, Portugal.
Sade - Publicação de caráter popular do S.N.E.S. - Ano XII - Almanaque de 1959 - Ministério da Saúde - Rio de Janeiro, Brasil.

Social Security Bulletin - April, 1959 Vol. 22 - Number 4.

La Scienza Tecnica Della Organizzazione Nelle Pubbliche Ammin'strazioni - Ano V - Gennaio/Marzo - 1959 - Milão. Itália . 